\title{
ENVOLVIMENTO E EMPATIA: A SOLIDARIEDADE CONSTRUÍDA NAS COLUNAS DE ACONSELHAMENTO EM REVISTAS
}

\author{
Paulo Roberto GONÇALVES-SEGUNDO ${ }^{1}$ \\ Rafaela Baracat RIBEIRO²
}

\begin{abstract}
Resumo: Nosso objetivo, neste trabalho, é depreender, baseado na abordagem sistêmicofuncional (HALLIDAY, 2004; MARTIN; WHITE, 2005), possíveis realizações do efeito empatia-antagonismo, conforme o modelo de Cameron (2011a, 2011b, 2011c, 2012a, 2012b), a partir da inscrição de recursos da rede de ENVOLVIMENTO, proposta após uma revisão e ampliação da sistematização oferecida em Gonçalves-Segundo (2011). Para atingir este objetivo, investigamos a prática discursiva de aconselhamento em revistas de nicho para homens adultos, mulheres adultas e mulheres adolescentes, uma vez que tais práticas consistem em lugar relevante para construção do estreitamento do vínculo interpessoal entre a instituição e o leitor que busca, na revista, uma potencial solução para situações-problema típicas de sua identidade social, o que pode favorecer a instanciação de formas especialmente empáticas na resposta da revista. Os resultados apontam - majoritária, mas não exclusivamente - para a correlação entre os recursos de ENVOLVIMENTO ligados à vinculação e os gestos de empatia entrar na perspectiva do outro e permitir a conexão, o que sinaliza padrões interacionais que enfatizam solidarização e gerenciamento interpessoal baseados, por um lado, em partilha de experiências e, por outro, no reconhecimento e na sensibilização em relação ao problema do outro.
\end{abstract}

Palavras-chave: Solidariedade. Envolvimento. Empatia.

\section{Introdução}

Este trabalho tem por objeto de estudo o envolvimento interpessoal constituído em textos de revistas de nicho, mais especificamente na seção de cartas voltadas ao

\footnotetext{
${ }^{1}$ USP - Universidade de São Paulo - Faculdade de Filosofia, Letras e Ciências Humanas - Departamento de Letras Clássicas e Vernáculas. São Paulo - São Paulo - Brasil. 05508-900. paulosegundo@usp.br

${ }^{2}$ USP - Universidade de São Paulo - Faculdade de Filosofia, Letras e Ciências Humanas - Departamento de Letras Clássicas e Vernáculas. São Paulo - São Paulo - Brasil. 05508-900. rafaela.baracat@usp.br
}

http://dx.doi.org/10.21165/gel.v13i2.835

Revista do GEL, São Paulo, v. 13, n. 2, p. 211-236, 2016 
aconselhamento. Com base em uma abordagem sistêmico-funcional, buscamos verificar casos de intersecção entre alguns recursos linguísticos de ENVOLVIMENTO ${ }^{3}$ com ocorrências de empatia nesse contexto de interação.

Partimos do pressuposto de que tais efeitos talvez se sobressaiam dada a natureza de recomendação dos textos sob análise. Estruturada por perguntas de leitores e respostas dos conselheiros, essa seção das revistas configura uma espécie de consultoria oferecida pelo periódico para sanar dúvidas e dilemas de seus consumidores textuais, em geral sobre comportamento. Para tal, constroem-se relações com base na espontaneidade e na busca de estreitamento da distância interpessoal entre produtor textual e nicho consumidor.

Tal natureza de proximidade, característica dos textos da coluna de conselhos, favorece a investigação dos recursos de que se vale a instância de produção textual para envolver a instância de consumo, bem como a verificação de quais recursos de ENVOLVIMENTO também instanciam gestos de empatia-antagonismo.

Para tanto, na primeira parte, expomos a fundamentação teórico-metodológica que serviu de base para a análise desenvolvida na segunda parte, em que são apontados os modos de se criar e realizar a troca concomitante de significados de envolvimento e empatia. Em seguida, apresentamos os resultados e as considerações finais.

\section{Fundamentos teórico-metodológicos}

Adotamos como perspectiva teórico-metodológica a Linguística Sistêmico-Funcional (LSF) proposta por Halliday (2004[1985]), que, ao tomar como referência a produção e o uso da linguagem, parte de uma concepção de língua como potencial sociossemiótico para construção e troca de significados. Nesse sentido, a língua é vista não só como sistema, mas como forma de conhecimento associada à organização de nossa experiência e como recurso para a atuação e a interação com o ambiente e entre os indivíduos. Por isso, a significação consiste em aspecto central do modelo, o que torna fundamental a análise de dados reais, materializados em textos, que consideram a complexidade da interação entre o contexto

\footnotetext{
${ }^{3}$ Adotaremos, de acordo com a notação sistêmico-funcional, os seguintes parâmetros de formatação: VERSALETE para nomes de sistemas e subsistemas; iniciais maiúsculas para categorias léxico-gramaticais, como Ator, Tema ou Sujeito; minúsculas para opções paradigmáticas em um sistema arbóreo. Para fins expositivo-visuais, contudo, também usaremos negrito nesse último caso. Assim, as folhas - opção mais refinada da árvore - do sistema de envolvimento, expostas posteriormente, ficarão no seguinte formato: coletivização inclusiva.
} 
sociocultural e situacional, tanto para descrever o sistema quanto para compreender o uso, que está intimamente ligado a padrões representacionais, acionais e identitários ${ }^{4}$.

Trata-se de um modelo que propõe um continuum entre sistema e texto e que assume que a relação entre língua e contexto ocorra de modo estratificado: os níveis externos - contexto cultural e contexto situacional - são realizados pelos níveis internos - a camada de conteúdo, composta pelos estratos semântico-discursivo, referente aos significados, e léxico-gramatical, referente aos fraseados -, que são manifestados pela camada de expressão, composta pelo estrato fonológico/grafológico, referente aos sons/grafemas.

Entendido como "um evento intersubjetivo, no qual falante e ouvinte trocam significado em um contexto de situação" (WEBSTER, 2009, p.7) ${ }^{5}$, o texto compreende um conjunto de escolhas do sistema linguístico, cuja configuração do contexto situacional dá conta dos fatores imediatos que influem nas escolhas linguísticas para a sua realização, por meio de três variáveis ou parâmetros, sistematizados por Halliday (1994/1978) em: Campo (field), Relações (tenor) e Modo (mode). Tais variáveis do contexto relacionam-se à organização metafuncional da língua, em termos ideacionais, interpessoais e textuais, bem como atravessam todos os estratos, do contexto à fonologia/grafologia. Combinatórias específicas de valores dessas três variáveis geram uma configuração contextual, que, por sua vez, ativa padrões linguísticos preferenciais de construção, denominados Registro ${ }^{6}$.

Assim, a dinamicidade de criação de significado resulta da seleção de determinados recursos dentre as opções do sistema linguístico para a construção de uma unidade de interação, em determinado contexto. Nesse sentido, para Lemke (2005, p.142, itálico do autor), o significado de uma ação "consiste em relações e sistemas de relações de relações. Estas relações são, basicamente, relações de contextualização" ${ }^{17}$, pois resultam da combinação de recursos de conteúdo e de expressão (relações sintagmáticas) feitas em dado contexto a partir da seleção de determinados recursos linguísticos dentre as opções disponíveis (relações paradigmáticas).

Desse modo, a realização dos significados é regida pela noção de metarredundância: alternativas estão em relação com outras, e um elemento é esperado a se passar com outro para que uma ação tenha sentido. Como os dois tipos de relações não são independentes, a

\footnotetext{
${ }^{4}$ Para maiores detalhes, sugerimos a leitura de Gonçalves-Segundo (2014) e Matthiessen (2012).

${ }^{5}$ No original: "A text is an intersubjective event, in which speaker and listener exchange meaning in a context of situation".

${ }^{6}$ Cabe destacar que, no âmbito da LSF, há duas posições a respeito: aquelas que igualam a configuração contextual ao registro (Martin, 1992, por exemplo), e aquelas que veem o registro como os padrões linguísticos metafuncionalmente orientados que caracterizam uma configuração contextual (como Halliday e Hasan, 1989).

${ }^{7}$ No original: "Meaning consists in relations and systems of relations of relations. These relations are basically contextualizing relations [...]".
} 
"metarredundância é apenas uma maneira de descrever como a redundância, a relação ou conexão previsível de duas coisas, pode ser ela mesma redundante (isto é, ter uma conexão previsível) com outra coisa"8 (LEMKE, 2005, p. 143).

Essa concepção baseia-se, portanto, em uma visão probabilística, calcada na noção de língua como sistema semiótico sociocultural composto por recursos para se atingir determinados fins, e que leva em conta as relações que são feitas para se compor um texto. Como tais relações seguem critérios de escolha e combinação, dois significados podem ser constituídos ao mesmo tempo porque conectam duas redes de alternativas para estruturação do conteúdo semântico-discursivo em determinado contexto. É o que buscamos averiguar a partir de dois conjuntos: o ENVOLVIMENTO em relação com gestos de empatia e antagonismo.

Uma vez que o foco deste trabalho reside na metafunção interpessoal, a partir de um olhar semântico-discursivo para verificar um registro situado no processo sociossemiótico da recomendação ${ }^{9}$, é preciso considerar as duas variáveis que perpassam a dimensão contextual Relações: uma no eixo vertical - Poder - e outra no eixo horizontal - Solidariedade.

Martin e White (2005, p. 29-31), a partir dos estudos de Poynton (1985), explicam que ao eixo vertical Poder relaciona-se a noção de Status, que envolve variações de igualdade, reciprocidade ou diferença nas formas de tratamento, por exemplo. Etnia, geração, gênero, classe e tipo de relação são fatores que interferem na variação de posições de dominância ou deferência, afetando o modo de construção das relações sociais no sentido de quem pode e como pode se expressar perante o outro. Por sua vez, ao eixo horizontal Solidariedade relaciona-se a noção de contato, referente à negociação de intimidade e distância, realizada segundo os princípios de Proliferação e Contração, relacionados respectivamente à ideia de que, quanto mais próximo se é de alguém, mais significados estão disponíveis para troca e mais a intimidade se desenvolve, e à ideia de que, quanto mais se conhece alguém, menos explicitação é necessária para trocar significados, por haver um partilhamento de vivências e interações anteriores, de tal modo que nem todas as informações precisem ser expressas verbalmente para que a compreensão se faça.

A solidariedade não existe apenas em questões de concordância ou discordância, mas também de tolerância para pontos de vista alternativos, permitindo ao falante/escritor indicar

\footnotetext{
${ }^{8}$ No original: "Meta-redundancy is just a way of describing how the redundancy, the predictable relation or connection of two things, can itself be redundant (i.e. have a predictable connection) with something else. This is redundancy of redundancy, or meta-redundancy".

${ }^{9}$ Matthiessen (2009) aponta que estudos em perspectiva sistêmico-funcional têm desenvolvido análises de texto baseadas em aspectos do campo contextual, explorando a variação e tipologia de registros em diferentes processos sociossemióticos: explicar, reportar, recriar, compartilhar, fazer, recomendar, habilitar e explorar.
} 
que reconhece a existência da diversidade de pontos de vista e que está aberto para se envolver com aqueles que sustentam uma posição diferente (MARTIN; WHITE, 2005). Nesse caso, levam-se em conta as formas pelas quais o falante/escritor busca se alinhar com o leitor ideal, considerando o modo como valida ou invalida pontos de vista.

Trata-se de uma atividade de negociação que, segundo Martin e Rose (2007), concerne à interação como troca entre os falantes (à forma como se adotam e se atribuem funções de fala) e à forma de estruturar e realizar a troca (por meio de declarações, perguntas, ofertas ou comandos).

Uma vez que atua com recursos para negociar Relações, especialmente Solidariedade, o ENVOLVIMENTO é aqui entendido como um processo de gerenciamento das relações interpessoais para efetuar a solidariedade, mobilizado por princípios de tração e/ou de atração, forças que configuram a dinâmica do processo e movimentam a relação produtor-textoconsumidor.

Inspiramo-nos na linha proposta por Gonçalves-Segundo (2011), que desenvolveu uma primeira sistematização da rede de elementos pela qual se estrutura o ENVOLVIMENTO em língua portuguesa, como recursos linguísticos de criação de vínculos e de captação. Consideramos que vincular e captar podem ser associados à aplicação de força de tração e atração. A tração funciona como se fosse uma corda ou fio capaz de conectar um indivíduo ao outro. Assim, o produtor tem a possibilidade de estabelecer vínculos ao exercer esse tipo de força sobre o consumidor textual por meio de recursos de ENVOLVIMENTO. Já a aplicação da força de atração é exercida pelo produtor para tentar fazer com que o consumidor tenha o interesse despertado e a atenção captada para as representações construídas no texto.

Entre as categorias de realização do ENVOLVIMENTO, Eggins e Slade (1997) e Martin e White (2005) apontam algumas que funcionam para construir e variar o nível de intimidade de uma interação, tais como: nomeação; léxico técnico ou especializado; interjeições; gírias; palavras de baixo calão. No entanto, para Gonçalves-Segundo (2011), considerar que o ENVOLVIMENTO se restrinja a tais recursos léxico-gramaticais significa ignorar outras possíveis opções linguísticas e discursivas quando se leva em conta o processo de solidarização, tendo em vista que, em conformidade com o pesquisador, o envolvimento não requer apenas um olhar para a relação do produtor textual com o consumidor, mas também para a relação do consumidor com o texto. 
Com base nessa perspectiva, sinteticamente apresentamos os recursos da rede de ENVOLVIMENTO, encontrados no corpus $^{10}$ composto por textos da coluna de conselhos em revistas de nicho, a partir da ideia de que o produtor busca tracionar e/ou atrair o consumidor do texto via:

- COLETIVIZAÇÃo: os vínculos ocorrem por agrupamento ou ação conjunta, e pode ser realizada pela coletivização inclusiva, coletivização genérica e coletivização exclusiva.

- PESSOALIZAÇÃO: os vínculos ocorrem por particularização ou por demonstração de emoções e de sentimentos, que conferem um tom mais pessoal para estabelecer afinidade, intimidade e afeição. Pode ser realizada por meio de: pronominalização em primeira ou segunda pessoa do singular, nomeação e afetividade.

- COMPARTILHAMENTO: os vínculos ocorrem por partilha de vivências, realizado por construção de representações daquilo que se presume ser comum ou que possa corroborar pontos de vista e situações em comum $^{11}$.

- $\quad$ FILIAÇão: os vínculos ocorrem por inclinação ou alinhamento ao mesmo universo de representações, por meio de demonstração de pertencimento a um grupo social.

- DEMANDA: os vínculos e/ou a captação ocorrem na medida em que se requisita uma atitude participativa em relação às representações construídas no texto, seja por meio de indagação ou solicitação.

- NARRATIVA: os vínculos e/ou a captação ocorrem pela forma como se estruturam representações e posições valorativas, por meio de narrativas pessoais e não-pessoais, para se gerar interesse para o que é construído no texto ou tentar constituir efeitos de identificação ao trazer à tona acontecimentos que se encaixem ao que é tomado como objeto de discurso.

- $\quad$ PRESENÇA: a captação ocorre pela forma como se constroem representações e posições valorativas no texto, a fim de torná-las mais "concretas", "visíveis", "palpáveis". O

\footnotetext{
${ }^{10}$ Especificado nesta seção, mais adiante.

${ }^{11}$ Ao destacar a ideia de empatia como base, amplia-se a definição dada em Gonçalves-Segundo (2011). Para o autor, tal categoria relaciona-se à ideia de construção de pressupostos que o produtor textual julga serem comuns e supostamente aceitos, a fim de gerar a sensação de conhecimento mútuo e identificação. Entendemos que esta ideia possa ser abrangida ainda pela noção de conectar-se com o outro não só pelos indícios de compreensão e reconhecimento da perspectiva do parceiro (o que se presume ser comum), mas também pela apresentação de uma experiência que possa contribuir como apoio na contextualização das representações e posições construídas no decorrer da atividade interativa.
} 
modo de elaboração de uma ideia construída, para realçá-la e torná-la presente para que o outro possa apreendê-la, pode ser realizado por meio de figurativização e simulação.

- NOVIDADE: a captação ocorre pela inovação, de modo que representações e posicionamentos são construídos como algo que possa atrair pela originalidade ou pela criação de expectativas. O efeito de inovação pode ser realizado por meio de suspense, contraexpectativa e aglutinação.

Ao partirmos da perspectiva de que o ENVOLVIMENTO ocorre com a criação de pontos de conexão entre produtor-consumidor e entre consumidor-texto, representamos a rede de recursos depreendida das cartas de aconselhamento:

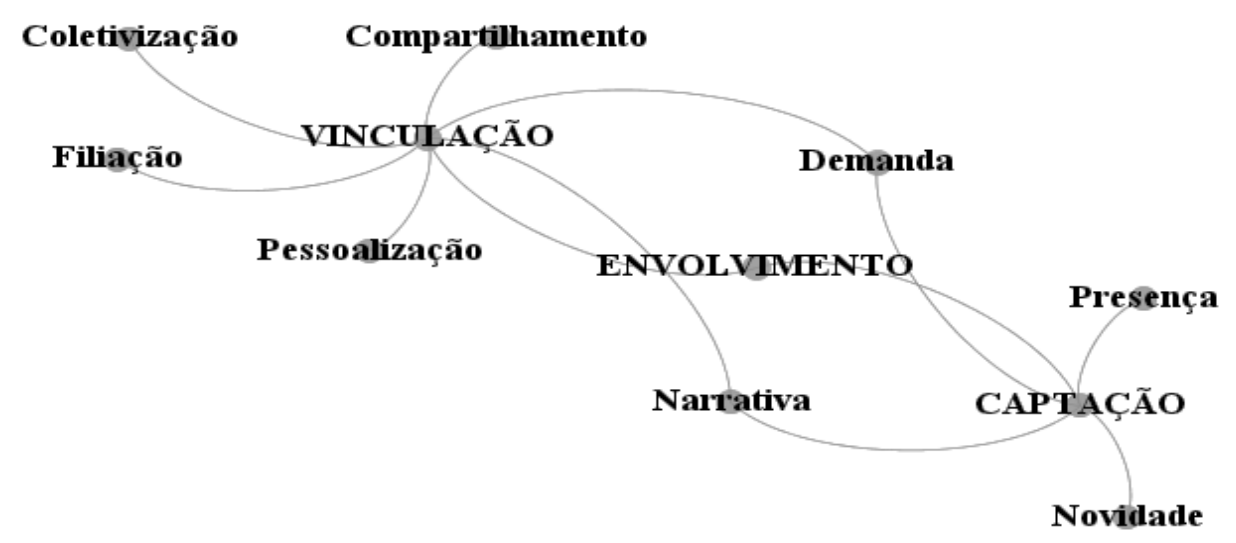

Figura 1. Representação da rede de envolvimento

Essa representação não segue a notação sistêmica em grafos arbóreos proposta pela LSF, mas sim uma apresentação em rede, porque desta forma tem-se a visão de que os recursos de envolvimento não obedecem a uma divisão hierárquica ou dicotômica, mas estão dispostos em zonas de contato, podendo funcionar em termos de maior/menor vinculação/captação.

No caso, focalizaremos, na atividade de conselhos, recursos que fazem parte dessa rede de ENVOLVIMENTO em interface com a noção de empatia. Para tanto, cabe destacar a visão de duas pesquisadoras que não trabalham com LSF, mas cujas ideias harmonizam-se com a concepção de um conjunto de alternativas que servem para criar envolvimento e empatia; tratase, respectivamente, de Deborah Tannen e de Lynne Cameron.

Tannen (1989, p.12) destaca a ligação resultante do encontro eu-outro no processo de envolvimento interpessoal, pois entende que este se trata de "uma conexão interna, até mesmo emocional, que os indivíduos sentem, que os vinculam às outras pessoas, como também a 
lugares, coisas, atividades, ideias, memórias e palavras" ${ }^{12}$. Ao analisar textos conversacionais e literários, a autora apresenta estratégias discursivas, tais como a repetição de palavras e frases, o uso frequente de imagens e descrição de detalhes, as figuras de linguagem, que orientam a percepção/compreensão do discurso e desencadeiam o envolvimento entre os participantes da atividade interativa.

Ao pensar o envolvimento como relações que ligam um indivíduo a outro, a concepção de Tannen remete a questões relativas à dialogia e à alteridade, assim como considera Cameron a respeito da empatia: perceber o "eu" no contato e em contraste com o "outro". Para Cameron (2011a), a complexidade da relação pessoal com o social, no que faz o outro distinto e diferente do $e u$, é o alicerce da dinâmica da expressão ou resistência à empatia, uma vez que as pessoas são levadas a pensar, sentir e agir com base na percepção ou na compreensão de um complexo de elementos distintos, que compõem a alteridade.

Com base nessa noção é que a pesquisadora aborda a empatia como processo que diz respeito ao ato de imaginar e tentar entender como o outro se sente em seu mundo. Assim, a autora considera que tal atividade pode ser acionada e expressa verbalmente, por meio de expressões faciais, de imagens, e por formas de ação social. A isso, Cameron (2011a) denominou "gestos de empatia" (gesture of empathy), relacionados a demonstrar aceitação, reconhecimento, colaboração e confiança.

Ao desenvolver estudos sobre a ocorrência desse fenômeno no diálogo, o modelo de empatia proposto pela autora baseia-se na caracterização de dois processos: a empatia emocional (emotional empathy - vista como instantânea e instintiva) e a empatia por tomada de perspectiva (perspective taking - concebida conscientemente, o que envolveria maior esforço cognitivo).

A empatia emocional é o processo de imaginar a si mesmo na situação do outro, uma capacidade de compartilhar experiências e emoções através de respostas imediatas à percepção do outro, enquanto a empatia por tomada de perspectiva ou controlada é um processo mais consciente de imaginar e tentar entender como o outro se sente em determinada situação a partir dos valores, crenças e sensações deste outro.

Em contrapartida, ocorre também na interação o antagonismo (dyspathy) ${ }^{13}$, que, segundo Cameron (2012b), refere-se a processos, capacidades e fenômenos de bloquear a

\footnotetext{
${ }^{12}$ No original: "[involvement is] an internal, even emotional connection individuals feel which binds them to other people as well as to places, things, activities, ideas, memories, and words".

13 Nos estudos brasileiros, antagonismo foi o termo adotado pelo GELP-COLIN - Grupo de Estudo sobre Linguagem e Pensamento - Cognição e Linguística - para se referir à dyspathy, na abordagem de discursos relativos à violência, a partir da proposta de Lynne Cameron.
} 
identificação com outra pessoa, evitar sentir-se na posição desse outro ou mesmo tentar compreender seu comportamento - um processo de resistência e fechamento de canais para conexão.

Nesse sentido, para além da empatia individual, há influências de ordem social na geração ou bloqueio da empatia. Alguns dos fatores são as afiliações sociais e as tendências ideológicas (bias) de um indivíduo, que estão em jogo favorecendo a empatia pela inclinação para membros de um mesmo grupo (endogrupo), ou desfavorecendo quando diz respeito a membros do outro grupo (exogrupo). Assim, pode haver maior resistência à sintonia emocional para ver o outro como aceitável social e/ou ideologicamente, na medida em que forças sociais operam inibindo a ativação da empatia, de forma que os membros do outro grupo são vistos como indignos de atenção ou percebidos como ameaçadores de alguma forma, como exemplifica a autora.

A reformulação de concepções a respeito do outro acontece tanto em uma escala microtemporal, a cada evento interacional, quanto em escala macrotemporal, ao longo das práticas sociais, pois, por um lado, atitudes e crenças que se estabilizaram ao longo de um período estão em jogo em diálogos futuros e tendem a influenciar o que é dito no curso de um evento de discurso, e, por outro, o que acontece no curso dos eventos interativos pode levar a instabilidades e a mudanças em relação a atitudes positivas que conduzem à empatia ou a atitudes negativas que a bloqueiam (CAMERON, 2011c).

No projeto de estudo sobre tais fenômenos, Living with Uncertainty ${ }^{14}$, Cameron tem verificado sua realização pela investigação do papel das metáforas utilizadas no diálogo e na interação, que apontam para o processo de permissão ou bloqueio da empatia, resultante da inclusão/exclusão do outro em relação ao espaço do eu. Os resultados da pesquisa indicam a emergência desse fenômeno no discurso por meio de três tipos de gestos de empatia (CAMERON, 2011b, p.12-15):

- Permitir a conexão - dar acesso ao pensamento e aos sentimentos sobre o passado, o presente e o futuro, estar disposto a compartilhar emoções com o outro, explicar e reviver acontecimentos, expor as razões para determinadas escolhas e comportamentos;

\footnotetext{
${ }^{14} \mathrm{O}$ projeto de Cameron dedica-se ao estudo da dinâmica empatia-antagonismo, isto é, preocupa-se com a forma como as pessoas "constroem empatia" em algumas situações e/ou de que maneira mudam de empatia para antagonismo, dando especial atenção às formas de categorização e às metáforas construídas em conversas de reconciliação pós-conflito.
} 
- Entrar na perspectiva do outro - compreender a visão de mundo do outro pelo que se sabe sobre suas experiências e emoções, reconhecer os sentimentos do outro, oferecer uma explicação ou argumento como contribuição de apoio, falar como se a partir da perspectiva do outro;

- Mudar a relação percebida de si e do outro - mostrar-se disposto a ouvir o que o outro tem a dizer, reposicionar o outro (por exemplo, de ser um inimigo para ser alguém com uma história para contar), reposicionar a si mesmo (por exemplo, de ser uma vítima para assumir alguma responsabilidade), reconhecer o que é compartilhado por ambos, eu e o outro.

Com base na perspectiva aqui exposta, verificaremos opções linguísticas de envolvimento para instanciar solidariedade e empatia ou antagonismo no contexto dos conselhos veiculados na seção perguntas e respostas de revistas voltadas a três diferentes segmentos sociais: masculino, feminino e adolescente.

A escolha do corpus se deu pelo caráter finalístico dos textos de aconselhamento, que procuram estabelecer uma relação mais espontânea ou próxima da interação cotidiana e que tendem a explorar aspectos da solidariedade, tendo em vista atingir o seu mercado consumidor. Os textos foram coletados aleatoriamente entre aqueles que estavam disponíveis nas homepages das revistas, cujas publicações impressas, em geral, são reproduzidas nas páginas da internet ${ }^{15}$. No total, foram coletados 120 textos, sendo 40 perguntas/respostas publicadas em cada um dos periódicos:

\begin{tabular}{|c|c|c|c|}
\hline Número de textos & Seção & Revista & Público alvo \\
\hline 20 & Pergunte à Vizinha ${ }^{16}$ & \multirow{2}{*}{ Men's Health } & \multirow{2}{*}{$\begin{array}{l}\text { Jovem adulto } \\
\text { masculino }\end{array}$} \\
\hline 20 & Pergunte ao Beto, o barman ${ }^{17}$ & & \\
\hline 20 & Pergunte ao Amigo Gay ${ }^{18}$ & \multirow{2}{*}{ Women's Health } & \multirow{2}{*}{$\begin{array}{l}\text { Jovem adulto } \\
\text { feminino }\end{array}$} \\
\hline 20 & Pergunte ao Vizinho ${ }^{19}$ & & \\
\hline 40 & Arrasa! Ficadas e rolos ${ }^{20}$ & Atrevida & $\begin{array}{l}\text { Adolescente } \\
\text { feminino }\end{array}$ \\
\hline
\end{tabular}

${ }^{15} \mathrm{O}$ período de coleta desse material deu-se entre agosto/2012 a abril/2014.

${ }^{16}$ Disponível em: 〈http://vip.abril.com.br/pergunte-a-vizinha/>.

${ }^{17}$ Disponível em: <http://vip.abril.com.br/especial-beto-o-barman/>.

${ }^{18}$ Disponível em: <http://mdemulher.abril.com.br/blogs/especialistas/categoria/amigo-gay/>.

${ }^{19}$ Disponível em: 〈http://mdemulher.abril.com.br/blogs/especialistas/categoria/pergunte-ao-vizinho/> .

${ }^{20}$ Disponível em: <http://atrevida.uol.com.br/arrasa/ficadas-e-rolos\#>. 
A partir de uma análise qualitativa desse conjunto, extraímos construções linguísticas que desempenham o papel de vincular e captar, para a composição da rede de recursos. Aqui, destacaremos apenas um conjunto de ocorrências, norteando-nos pelas seguintes questões: quais categorias de envolvimento funcionam com efeito empático e de que maneira são veiculados sentimentos de empatia ou antagonismo na prática de aconselhamento sob análise?

\section{Análise: entre os conselhos, o envolvimento e a empatia}

Quando o produtor do texto se insere como participante dos processos e representações ali construídos ou insere o interlocutor alvo, para particularizar a interação e conferir a esta um tom mais pessoal, vínculos podem ser estabelecidos, e efeitos de afinidade, intimidade e afetividade, instaurados. Na medida em que a instância produtora demonstra alguma forma de afetividade ou posicionamento favorável ao problema do leitor, pode-se criar uma conexão emocional que os vincula e assim envolve, como ocorre $\mathrm{em}^{21}$ :

(1) Namoro há quatro anos e não suporto meu cunhado e a esposa dele, que me tratam mal veladamente. Nos encontros de família, meu namorado e eu brigamos se reclamo do casal. Como dar um chega pra lá nos malas? ALLINE C., PA

Num mundo ideal, você deveria chamar seu cunhado e a mulher para uma conversa franca e indagá-los: "Por que vocês me tratam assim? Foi alguma coisa que eu fiz ou disse?" Talvez vocês descubram que tudo não tenha passado de um mal-entendido, fiquem com cara de bobos e depois façam as pazes. Só que, infelizmente, nosso mundo não é o dos mais ideais e um convite desses pode até piorar as coisas com essa duplinha do mal. Seu namorado poderia ser seu aliado, mas ele não parece disposto a ouvir críticas ao irmão... Portanto, o jeito mais simples de evitar uma guerra em família é não se incomodar mais. Encare-os como a parte chata do pacote maravilhoso que é o seu relacionamento e aguente firme.

Fonte: Women's Health, Pergunte ao Amigo Gay. Blog MdeMulher, 6 set. 2012. Disponível em: <http://mdemulher.abril.com.br/blogs/especialistas/categoria/amigogay/>

\footnotetext{
${ }^{21}$ Os segmentos em itálico consistem em conjuntos de construções linguísticas relevantes para a análise da correlação entre empatia e envolvimento. Não integram, portanto, o texto original.
} 
(2) A ex-mulher do meu namorado liga até de madrugada com desculpas esfarrapadas. Usa o filho deles para fazer muitas chantagens. Posso me intrometer e dizer que só aceitamos ligações no horário comercial? CINTHIA M., DF

Sinto informar, mas ela vai ter que falar com o seu namorado para todo o sempre. $\mathrm{Ou}$ pelo menos até o garoto se formar na faculdade e sair de casa. É muita empáfia da sua parte querer que a mãe do filho dele não possa ligar à noite: já pensou se acontece alguma coisa? Agora, não duvido que ela seja mesmo uma tremenda duma chantagista emocional e que tente de tudo para separar vocês dois. Mas esse problema é antes dele do que seu. Deixe-o domar a megera e meta-se nessa história o mínimo possível.

Fonte: Women's Health, Pergunte ao Amigo Gay. Blog MdeMulher, 6 set. 2012. Disponível em: <http://mdemulher.abril.com.br/blogs/especialistas/categoria/amigogay/>

Em (1), o aconselhamento inicia-se por um recurso de PRESENÇA que coloca em cena o "como" solucionar o problema por meio da simulação, pela qual se promove a solidariedade do produtor para com o consumidor textual por focalizar atenção àquilo que seria dito e dramatizado na interação face a face ("Num mundo ideal, você deveria chamar seu cunhado e a mulher para uma conversa franca e indagá-los: 'Por que vocês me tratam assim? Foi alguma coisa que eu fiz ou disse?"').

Dá-se continuidade ao processo de envolvimento por meio de uma forma de CAPTAÇÃO, realizada por contraexpectativa, que rompe com a sugestão anterior para focalizar o novo parecer a respeito do problema ("Só que, infelizmente, nosso mundo não é o dos mais ideais e um convite desses pode até piorar as coisas com essa duplinha do mal"). A contraexpectativa introduz a empatia manifestada em uma estrutura de envolvimento pela qual se partilham concepções $^{22}$. Por meio da expressão "essa duplinha do mal", o produtor do texto acena correspondência de pontos de vista com o problema apresentado pelo leitor, pois a referência ao elemento problema ("meu cunhado e a esposa dele") é partilhada por ambos de forma negativa ("malas" - "essa duplinha do mal").

Em (2), tem-se inicialmente uma expressão de afetividade seguida pela contraexpectativa que rompe, em parte, com a manifestação de sentimento pessoal sobre o problema ("sinto informar, mas"). O que é focalizado como atribuição válida é apresentado após o elemento que quebra a expectativa, aguçando a atenção do consumidor para o que será

${ }^{22}$ A construção de formas referenciais que convergem à perspectiva do outro realiza outra categoria de ENVOLVIMENTO que será tratada posteriormente, de modo mais específico: a VINCULAÇÃO: COMPARTILHAMENTO. 
dito ("ela vai ter que falar com o seu namorado para todo o sempre. Ou pelo menos até o garoto se formar na faculdade e sair de casa").

Segue-se a esse lamento um sermão a respeito do comportamento da leitoraquestionadora: "é muita empáfia da sua parte querer que a mãe do filho dele não possa ligar à noite". Deriva dessa construção repreensiva uma forma de antagonismo que cria um distanciamento do conselheiro em relação a esse tipo de atitude, o que parece justificar a atenuação anteriormente apresentada pela introdução da construção afetiva ("sinto informar").

Como se trata de uma prática de aconselhamento, é passível a ocorrência paralela entre aprovar e repreender condutas. Contudo, rompe o antagonismo a construção introduzida pelo marcador discursivo sequenciador "agora". A empatia, então, entra em cena quando o produtor textual não deixa de rejeitar totalmente o problema da leitora, ao apresentar sua concordância a respeito do que deduz ser o comportamento da ex-mulher e que imagina ser a representação vigente da leitura sobre esse objeto-de-discurso ("não duvido que ela seja mesmo uma tremenda duma chantagista emocional e que tente de tudo para separar vocês dois"). A tomada de perspectiva da situação da leitora leva o conselheiro a confirmar a representação da ex do namorado como "chantagista" e "megera". Em seguida, lança o foco para uma nova opinião ("Mas esse problema é antes dele do que seu"), aconselhando-a a não se interpor no assunto.

Dessa maneira, observamos como as construções destacadas podem constituir não só envolvimento, como também gestos de empatia e antagonismo que instauram uma relação solidária, apesar de haver instâncias pontuais de antagonismo para estabelecer o discurso do aconselhamento que envolve pela repreensão e pela compreensão. As expressões que externalizam um ponto de vista pessoal confirmam um posicionamento de apoio, bem como as expressões reveladoras da tomada de perspectiva pela representação avaliativa do elemento empecilho, construído como se fosse a partir do ponto de vista da leitora, apontam formas de empatia consciente, de reconhecimento da situação do outro.

Já o ENVOLVIMENTO criado pela PESSOALIZAÇÃO realizada pela pronominalização em primeira pessoa do singular caracteriza um modo de criar uma relação mais intimista, cujo efeito vai além de apenas revelar maior grau de subjetividade de quem emite o aconselhamento, como é o caso a seguir:

(3) Meu namorado, dez anos mais novo, me pediu em casamento. Sei que me ama, mas penso muito no futuro. Me imagino com 60, meio estragada, e ele com 50, todo bonitão. O que faço? CRIS R., ES 
Você não vai gostar da minha resposta, mas acho que precisa ficar ciente do risco que corre: sabe a chance de chover no Réveillon? É menor do que a possibilidade de ele trocar você por uma moça mais nova daqui a alguns anos. Digo isso porque já conheci muitos casais parecidos, e, invariavelmente, o homem acabou aprontando. Veja bem, não duvido que seu namorado a ame muito. Mas, ao chegar à tal da "idade do lobo", fica difícil para qualquer coroa resistir ao assédio das periguetes. Ainda mais se ele estiver envelhecendo bem e a mulher que ele tem em casa nem tanto. Não estou dizendo para você não se casar, já que toda regra tem exceção. Mas depois não diga que eu não avisei.

Fonte: Women's Health, Pergunte ao Amigo Gay. Blog MdeMulher, 6 set. 2012. Disponível em: <http://mdemulher.abril.com.br/blogs/especialistas/categoria/amigogay/>

Nessa troca interpessoal, duas questões precisam ser destacadas quanto ao uso da primeira pessoa do singular: a primeira é que pode funcionar discursivamente como forma de desinstitucionalizar o grau de autoridade que uma possível opção pela coletivização exclusiva ${ }^{23}$ acarretaria; a segunda é que, quando ocorre dentro de uma estrutura de COMPARTILHAMENTO, pode-se gerar um efeito empático.

Assim, em "minha", "acho...", "não duvido...", "não estou dizendo..." e "eu não avisei", a posição do produtor do texto-resposta é construída de maneira mais pessoal que se o conteúdo fosse expresso de modo exclusivista e, assim, mais institucionalizado. Desse modo, optou-se por estabelecer uma interação particularizada para simular um contato mais próximo com o leitor.

Já em "Digo isso porque já conheci muitos casais parecidos, e, invariavelmente, o homem acabou aprontando", a construção em primeira pessoa, ao fazer parte da estrutura de COMPARTILHAMENTO pela qual se expressa uma experiência particular, indica empatia na medida em que o produtor textual reconhece a essência do problema da leitora e oferece a ela uma espécie de assistência, ao compartilhar algo já vivido, para reforçar o conselho ("ficar ciente do risco que corre") a quem passa por determinada situação. Podemos considerar a construção como gesto de empatia, pois se permite uma conexão quando se compartilha e explica para o outro as razões para determinados comportamentos e escolhas, o que possivelmente viabiliza a confiança e a aceitação dos conselhos.

\footnotetext{
${ }^{23}$ Cabe apontar que o modo prototípico de realizar a categoria coletivização é pelo uso da primeira pessoa do
} plural. 
Entendemos o COMPARTILHAMENTO como categoria que desempenha a função de envolver no seguinte sentido: o produtor textual traciona o consumidor pela demonstração de solidariedade, ao partilhar e repartir com ele vivências que possam ajudá-lo a compreender as representações e propostas construídas no texto. Dessa maneira, dá-se a conhecer experiências sobre aquilo que se presume ser um fator comum em relação a sentimentos, emoções e desejos do outro, que possam corroborar pontos de vista e potencializar o efeito argumentativo do aconselhamento ao apresentar situações semelhantes.

Nesse sentido, verificamos que o COMPARTILHAMENTO de uma experiência análoga ao problema do leitor, um gesto de empatia, serve ao ENVOLVIMENTO, na medida em que permite conexão com o outro, criando vinculação e solidariedade. Uma vez imbuída de gestos de reconhecimento e identificação com o problema apresentado, conforme se observa no trecho em destaque em (4), a construção empática se constitui por meio da pronominalização em primeira pessoa ("já passei por isso"), seguida da partilha de um processo similar que se vivenciou. Verifica-se aqui um caso de empatia emocional:

(4) Uma amiga sempre se afasta quando está namorando. Então, quando não dá certo, espera voltar ao posto de best friend. Algum conselho? PATRICIA P., PR

Que tal não atender o telefone? Ou dizer que tem outro programa? Já passei por isso. Um amigo mais folgado que camiseta velha só me procurava quando estava solteiro. Adivinha? Ele casou e sumiu para sempre. Portanto, continue tratando bem essa mulher-pêndulo, mas apresente logo a ela a sua verdadeira melhor amiga, a quem você conheceu durante o longo período em que se sentiu abandonada pela fofa.

Fonte: Women's Health, Pergunte ao Amigo Gay. Blog MdeMulher, 6 set. 2012. Disponível em: <http://mdemulher.abril.com.br/blogs/especialistas/categoria/amigogay/>

Acresce-se a essa estrutura de COMPARTILHAMENTO o recurso de DEMANDA no âmbito da indagação, na tentativa de fazer com que a leitora participe mais ativamente da interação. Com base nesse processo, a empatia é constituída ainda pela demonstração favorável de posicionamento que toma partido da situação e constrói negativamente as atitudes de quem ofendeu os sentimentos da leitora. Isso se observa tanto pela construção metafórica, orientada pela ideia de que pessoas são coisas, quando se associa a amiga que some quando namora a traços de objetos que se identificam à pessoa relapsa e oscilante ("mais folgado que camiseta velha" e "essa mulher-pêndulo"), quanto pela ironia instaurada por uma referência com sentido 
pragmaticamente negativo ("abandonada pela $f \circ f a "$ ), uma vez que o sentido de delicadeza do termo "fofa" não é traço de atitude de uma pessoa que se afasta por um período. Portanto, há, nesse processo, elementos de empatia por tomada de perspectiva do outro.

Outros exemplos do uso do recurso de COMPARTILHAMENTO em conjunto com a PESSOALIZAÇÃo são verificados quando o produtor textual mostra que reconhece determinadas situações apresentadas, expressando sua consideração e compreensão para com o problema da leitora, o que gera, por consequência, a empatia, como se observa em (5) e (6):

(5) Ultimamente, qualquer desentendimento com meu namorado vira uma briga imensa. Como acabar com a guerra? GABRIELA J., POR E-MAIL

Infelizmente, com mais guerra. Se vocês já estão nesse ponto bélico, é porque há temas de desconforto que não estão sendo ditos. E vou lhe dizer que o não dito acaba se manifestando de várias formas, inclusive em desentendimentos corriqueiros. Sei que é difícil e que várias pessoas evitam esses confrontos, mas verdades que incomodam a ambos terão que ser discutidas seriamente e perdoadas.

Fonte: Women's Health, Pergunte ao Vizinho. Blog MdeMulher, 28 ago. 2012. Disponível em: <http://mdemulher.abril.com.br/blogs/especialistas/categoria/pergunteao-vizinho/>

(6) "Voltei de uma viagem que durou as férias inteiras, cheguei até a matar o primeiro dia de aula. E, quando chego, pego meu namorado beijando a minha amiga! E pior, todos os nossos amigos sabiam e não me contaram nada. Me senti traída, não só pelo meu ex, mas por todos. Quero deixar isso pra trás, mas é difícil, pois preciso conviver com eles todos os dias. O pior é que meu ex fica me mandando mensagem pra saber se eu tô bem! O que eu faço? Quero fugir do mundo inteiro e me enterrar no meu quarto!” M.W., 14 ANOS

M., realmente é uma situação chata, mas se isolar dos seus amigos não é a melhor saída. Saber de uma traição, ainda mais entre pessoas do mesmo grupo, não é uma situação fácil. Tente se colocar no lugar deles e você vai perceber que ter esse tipo de conversa exige muito cuidado. A situação é diferente com o seu ex-namorado e a sua amiga, já que são as duas pessoas que de fato traíram a sua confiança e com quem você precisa conversar quando achar que é o momento certo. A melhor política é a honestidade. Enquanto esse momento não chega, lembre-se que você não fez nada errado e não há motivo para se esconder, ok? 
Fonte: Atrevida online, 7 abr. 2014. Arrasa! Ficadas e rolos. Disponível em: 〈http://atrevida.uol.com.br/arrasa/ficadas-e-rolos $>$

As construções destacadas revelam escolhas de que o produtor textual lança mão para partilhar sentimentos a respeito da situação exposta e sinalizam empatia pelo ato de posicionarse no lugar do outro e ofertar-lhe apoio por meio de respostas afetivamente compreensivas em relação ao que foi posto em causa. $\mathrm{O}$ gesto de entrar na perspectiva daquele que vivencia o problema se realiza com a manifestação de posicionamento em relação à adversidade vivida pela leitora ("Infelizmente, com mais guerra") e com formas de antecipação de suas reações, que endossam como o conselheiro se alinha a ela, por meio de construções que respondem a eventuais vozes antagônicas a respeito do problema (saber que foi traída pela amiga): "sei que é difícil", "realmente é uma situação chata" e "não é uma situação fácil".

Desse modo, para que o consumidor textual sinta que a revista não é apenas uma fonte ou manual de informação que vai lhe ajudar a resolver um problema, a escolha por um recurso de PESSOALIZAÇÃO, aliado ao COMPARTILHAMENTO, torna-se fundamental para a geração de empatia, como também se verifica no caso a seguir:

Oi, Atrê! Eu estava namorando por nove meses e o garoto terminou comigo. Já tentei ficar com outro pra ver se o esquecia, mas não funcionou. Ultimamente tenho andado triste, mas tentando me ocupar o máximo possível. Tenho saído muito com a minha BFF e meus outros amigos. Atualmente até ouvir música tem sido difícil. Todas me lembram dele, até porque ele sempre cantava músicas do One Direction pra mim. Estou muito triste mesmo. Não sei mais o que fazer. Tenho chorado todas as noites. Por favor, eu preciso muito da ajuda de vocês! Muito mesmo! C.L., POR E-MAIL

Dói muito mesmo, C., e nessa hora não adianta alguém dizer que isso vai passar, ou que o coração de todo mundo um dia já ficou apertado assim por um amor perdido. Mas se você escreveu pra Atrê é porque espera que eu diga algo e eu direi: respeite seu sentimento - mas deixe a porta do coração aberta. Ele mesmo poderá voltar se perceber que ama você. Mas também poderá vir alguém novo, e nem mesmo você pode garantir que não virá ou que não será um amor ainda melhor, por mais impossível que isso pareça hoje. A vida sempre surpreende!

Fonte: Atrevida online, 24 set.2013. Arrasa! Ficadas e rolos. Disponível em: 〈http://atrevida.uol.com.br/arrasa/ficadas-e-rolos $>$ 
Simulando uma conversação com a amiga mais próxima, a adolescente inicia a pergunta para a revista tratando-a com intimidade, por meio da PESSOALIZAÇÃO construída por cumprimento e nomeação abreviada investida de afeto ("Oi, Atrê!!"), para demandar-lhe auxílio ("Por favor, eu preciso muito da ajuda de vocês!"). Dessa forma, a seção de aconselhamento assume o papel de uma amiga que presta orientação para as decisões a serem tomadas com relação a algumas condutas do cotidiano, pois a revista incorpora esse papel e simula ser uma pessoa, como se verifica na introdução da oferta dos conselhos por meio de uma construção em primeira pessoa ("se você escreveu pra Atrê é porque espera que eu diga algo e eu direi").

Ao assumir a função de ser humano dotado de capacidade para agir e sentir, a revista constrói um gesto de empatia quando demonstra sua sensibilidade ao simular no "eu" a emoção de que compartilha com a adolescente ("Dói muito mesmo, C."), antecipando seu discurso de dor em relação ao problema. Colabora para isso, nesse caso, o recurso de ENGAJAMENTO ("mesmo"), do campo da concordância ${ }^{24}$, atuando na construção da empatia, por confirmar as expectativas de compreensão dos sentimentos da leitora, intensificando a força de vinculação no processo de envolvimento.

Também projeta efeito empático o COMPARTILHAMENTO efetuado pela apresentação de experiências pessoais, partilhadas pelo produtor do texto, de modo a permitir a conexão pelo acesso a vivências que possam funcionar como explicação ou argumento para que o consumidor textual se identifique e assim seja envolvido por meio do estabelecimento de vínculos:

Betoneira, guardo tão bem meus documentos que não os encontro. Minha namorada diz que faço bobagem. Será? F.T., SÃO PAULO - SP

Fica tranks, Éfetê. Não encontrar objetos guardados acontece com todo mundo - pior é que eles só aparecem quando não queremos mais! Sua garota deve estar procurando um motivo para pegar no seu pé. Conheço muitas mulheres que adoram esse esporte. Praticam ainda mais quando a relação começa a deteriorar. Agora, sério mesmo é esquecer o aniversário dela ou a carteira quando saírem. Quer um segredo de organização (aqui no balcão é batata)? Guarde todos os documentos sempre no mesmo lugar. Não dá chabu.

\footnotetext{
${ }^{24}$ A noção de concordância refere-se aos recursos linguísticos de ENGAJAMENTO abordados pela Teoria da Avaliatividade, proposta por Martin e White (2005). Os autores enfocam recursos relacionados à função interpessoal, em nível semântico-discursivo, realizados por diferentes categorias léxico-gramaticais que indicam o posicionamento intersubjetivo do falante/escritor, pelo modo como avaliam/julgam pessoas, objetos, atos, eventos. O ENGAJAMENTO compreende as formas pelas quais o produtor textual reconhece ou não outras concepções de realidade em face das suas e de que modo se alinha ou não com elas, por meio de construções linguísticas que possam expandir ou contrair o espaço dialógico.
} 
Fonte: Men's Health, n.74, jun.2012. In: Men's Health, Especial Beto, o barman, 2 jan. 2013. Disponível em: 〈http://vip.abril.com.br/especial-beto-o-barman/>

Partindo da afirmação de algo que considera que acontece comumente no cotidiano (perder coisas e encontrá-las quando não mais as quer), o conselheiro procura aumentar o grau de aceitabilidade pelo leitor ideal das representações que expressa por meio do COMPARTILHAMENTO de uma vivência própria ("conheço muitas mulheres que adoram esse esporte"), seguido da representação de que namoradas em geral têm o costume de importunar o parceiro quando o relacionamento dá sinais de que está acabando.

Essa concepção foi construída pelo recurso de PRESENÇA, via figurativização metafórica constituída pela ideia de que relacionamento se associa a jogo. Esse traço relativo ao domínio conceitual de "esporte" é projetado para o comportamento feminino em relações amorosas. Trata-se de uma conjectura construída como se fosse algo próprio do condicionamento feminino ou um ato recreativo das mulheres, assim como a ideia de que mulher leva em conta o lado financeiro numa relação, pois o esquecimento da carteira, além da data de aniversário, é apontado como elemento causador de problemas mais sérios em relacionamentos, como se verifica em "Agora, sério mesmo é esquecer o aniversário dela ou a carteira quando saírem". Nesse caso, a captação por suspense poderia, portanto, associar-se a uma atitude antagônica.

Contudo, observamos que o antagonismo não é construído em relação ao consumidor potencial dos textos (o jovem homem adulto), mas parece ser uma forma de ENVOLVIMENTO imbuída de uma visão antagônica em que se manifesta disposição para criar conexão apenas com membros do grupo masculino, repelindo possível identificação com aqueles que não compartilham dos mesmos pontos de vista. Entendemos que ocorre o bloqueio de uma reação de complacência efetuado pelo desfavorecimento de membros de outro grupo (exogrupo), no caso, mulheres.

Diferentemente do caso anterior, nos textos seguintes, observamos como gestos de empatia, tais como os realizados pela expressão dos próprios sentimentos sobre o problema do outro, aliam-se a outros meios de ENVOLVIMENTO, o qual pode ter seu efeito potencializado:

(9) Acho que ele está afim de uma amiga minha. E agora?

O boy dos seus sonhos gosta de sua amiga? Complicado, né? Saiba como agir!

"Sou apaixonada por um garoto há nove anos. Só que tenho vergonha de chegar nele e falar o que sinto e não ser correspondida, já que sempre falaram que a gente faz um belo 
casal e que nos amamos - só que sempre negamos gostar um do outro. Uma amiga minha também gosta dele e acho que ele também está a fim dela. Realmente estou confusa, não sei para quem contar.” B. T., POR E-MAIL

B., vamos refletir juntas? Considerando que vocês se gostam e até as pessoas acham que vocês formam um belo casal, o que vai acontecer se você falar com o garoto sobre seus sentimentos? Ok, você não sabe (que medão)! Mas não precisa dizer na lata. Usando seu charme e criatividade, garanto que você encontrará um jeitinho de fazê-lo entender. E o que acontecerá se você não falar? Pelo jeito, nada. Do que você se arrependerá mais com o tempo: de ter falado ou de não falar? Confie no seu taco!

Fonte: Atrevida online, 11 mar. 2013. Arrasa! Ficadas e rolos. Disponível em: 〈http://atrevida.uol.com.br/arrasa/ficadas-e-rolos $>$

(10) O menino que eu amo só quer ficar. E agora?

Descobriu que o seu grande amor não quer algo sério? Saiba o que fazer!

"Conheci um garoto, e ficamos super amigos, passamos a nos falar todo dia por telefone. Ficamos e até rolou mais que beijos. Ele diz que somos amigos coloridos. No início era só isso mesmo, só que descobri que estou apaixonada por ele, e não tenho coragem de dizer isso e nem de admitir. Ele disse que não sente nada por mim quando conversamos sobre isso, e eu neguei na hora que ele perguntou se eu gostava dele. Mesmo depois dessa conversa, ele me liga quase todo dia e passamos horas no telefone. Aos sábados marcamos de sair e sempre ficamos. E eu sei que para ele é só isso, pois o conheço bem, ele é do tipo "galinha", e diz que se eu gostar dele é pra dizer, pois não quer me magoar. Eu quero dizer o que eu sinto, mas eu tenho muito medo de perder isso que temos. Ajudem-me!" - V. S. 16 anos, por e-mail

Fonte: Atrevida online, 1 jul. 2013. Arrasa! Ficadas e rolos. Disponível em: 〈http://atrevida.uol.com.br/arrasa/ficadas-e-rolos $>$

Em (9), a primeira construção da chamada da revista simula a voz do público alvo potencial, uma vez que é formulada na primeira pessoa do discurso ("Acho que ele está afim de uma amiga minha"), seguida por uma indagação carregada de suspense sobre como será resolvido o problema ("E agora?"), que constituem formas de ENVOLVIMENTO por firmação de vínculos e pontos de atração.

A segunda chamada apresenta-se na voz da revista, que busca captar a consumidora demandando-lhe uma pergunta formulada com expressão comumente utilizada pelas 
adolescentes para se referir aos meninos ("O boy dos seus sonhos gosta de sua amiga?") na tentativa de também envolver fazendo uso de recurso de FILIAÇÃO, pelo qual o produtor busca tracionar a consumidora do texto para com ele conectar-se por meio de demonstração de pertencimento, inclinação ou alinhamento ao mesmo universo de representações, pelo modo que utiliza a linguagem.

Segue-se a essa DEMANDA outra construção indicativa de empatia: "Complicado, né?", pela qual se expressa um gesto afetivo de compreensão do problema da adolescente que se encontra na situação de gostar de um menino que parece não corresponder porque está a fim da amiga. Isso se verifica pela solicitação de anuência, feita por meio do marcador discursivo interacional, indicativa de que o conselheiro compartilha e entende ser a mesma visão da leitora (uma situação complicada). Por conseguinte, outra forma de ENVOLVIMENTO se constitui pela chamada promissora para resolver a questão ("Saiba como agir!"), construída por DEMANDA por solicitação, incitando a consumidora textual a ler a pergunta e a resposta para conhecer a solução do problema.

A pergunta propriamente dita aparece entre aspas para indicar a voz da leitora contando qual é a situação, o que consideramos configurar uma narrativa pessoal com potencial efeito empático, na medida em que se pode criar identificação com as consumidoras que vivenciam o mesmo dilema.

Em vista dos problemas relatados pela leitora, o conselheiro busca mais uma vez envolver pelo recurso de coletivização inclusiva e pela DEMANDA na forma de proposta realizada pela indagação ("B., vamos refletir juntas?"). O entrelaçamento desses recursos projeta efeito empático pelo ato de o produtor textual mostrar-se disposto a engajar-se em uma atividade conjunta e assim dar assistência ao problema da adolescente, a fim de que a relação seja estabelecida com base na afinidade e na confiança, permitindo-se, assim, a conexão, conforme Cameron (2011b).

Em (10), observamos que o envolvimento é realizado estrategicamente pela revista voltada às adolescentes, quando apresenta as perguntas das leitoras por meio de suas próprias narrativas. Primeiramente, o tópico é exposto para uma prévia captação da consumidora, a respeito do tema a ser desenvolvido na resposta ("O menino que eu amo só quer ficar"). A fim de que as potenciais consumidoras possam se identificar e se envolver com a situação, bem como despertar o interesse para a resolução do problema, também observamos a recorrência a recursos de DEMANDA. No caso, esse recurso foi realizado por meio de indagações, que realçam a dúvida sobre como resolver o impasse (“E agora?”, "Descobriu que o seu grande amor não 
quer algo sério?"), e, por meio de solicitação, construída por comando, na tentativa de aguçar a curiosidade de conhecer a solução-resposta (“Saiba o que fazer!”).

Só então é apresentada a pergunta com o desenvolvimento dos detalhes do tópico discursivo, que funciona como uma narrativa pessoal, pois, construída na voz da leitora, parece servir mais como depoimento de experiências a respeito do assunto. Desse modo, o envolvimento se constitui pela apresentação de uma estrutura pela qual se partilham situações então vivenciadas, conferindo veracidade ao que foi tematizado, para que uma possível identificação com a instância de consumo do texto ocorra. Nesse sentido, essa narrativa pessoal pode gerar um efeito empático, na medida em que se permite a conexão emocional pelo reconhecimento de problemas semelhantes.

No caso a seguir, a construção em destaque no texto-resposta revela como o conselheiro se vale também de um recurso do sistema de NARRATIVA, investido de COMPARTILHAMENTO, como forma de envolver e se solidarizar com a leitora. Um acontecimento atribuído a terceiros é relatado e serve de modelo ou lição para os conselhos oferecidos, e o conhecimento de uma experiência pessoal é partilhado para tentar explicar as razões para determinados pontos de vista:

(11) Como superar o fim do namoro com aquele que eu acreditava ser o homem da minha vida? ANA CAROLINA S., POR E-MAIL

Seguindo a lógica cartesiana, se ele fosse o homem da sua vida, estaria com você. Logo, não é. O primeiro passo é aceitar isso. De verdade. O segundo é saber (e sentir) que a vida não acabou. Que ela ainda lhe reserva surpresas, amores e alegrias. Recentemente uma amiga foi cantada por um homem que estava sentado ao seu lado em um teatro. E estão completamente apaixonados. Segundo ela, é o homem da sua vida (depois de ter tido outros, claro). Detalhe: ela tem 68 anos. A moral da história é que nós nunca sabemos como o destino se apresentará e, definitivamente, não existe limite de idade para o amor.

Fonte: Women's Health, Pergunte ao Vizinho. Blog MdeMulher, 24 ago. 2012. Disponível em: <http://mdemulher.abril.com.br/blogs/especialistas/categoria/pergunteao-vizinho/>

A representação construída realça para a leitora um modo de encarar a situação e apreender a ideia passada a partir de determinada perspectiva. Dessa maneira, a NARRATIVA não pessoal reenquadra como conselho um acontecimento do qual a leitora pode tirar uma lição 
de vida, configurando um recurso que não só serve para captar a atenção, como também tornar o processo interpessoal mais intimista, uma vez que certas informações são compartilhadas como uma espécie de testemunho.

Reforça o processo de aconselhamento a construção "O primeiro passo é aceitar isso. De verdade. O segundo é saber (e sentir) que a vida não acabou", pela qual o conselheiro vincula-se à leitora, tentando mudar a percepção que se tem a respeito do problema vivido. Enquanto a expressão "de verdade" sinaliza que é preciso entender que o fato já passou e que a situação atual deve ser assumida, antecipando uma possível resistência da leitora, o que sinaliza um gesto de empatia por tomada de perspectiva, a construção "saber (e sentir)" aponta o aspecto racional reforçado pelo emocional, que responde contra o discurso de que a vida acaba por conta do fim de um namoro. Como consequência, a empatia pode ser instaurada por esse ato de compartilhar experiências de terceiros, as quais servem como endosso e como contribuição de apoio ao conselho implicitamente construído (como nunca é tarde para amar, siga e seja feliz com o rumo que a vida tomar).

Nesse sentido, recursos como COMPARTILHAMENTO e NARRATIVA podem não só funcionar como forma de envolvimento nas relações sociais, ao conectar a leitora ao conselheiro e às suas ideias, do ponto de vista interno e emocional nos termos de Tannen (1989), mas também ter potencial para evocar empatia, pois, ao se relatar emoções, simular uma situação ou narrar experiências pessoais, permite-se acesso ao outro, possivelmente impactando-o, tendo em vista a experiência que é dramatizada, segundo Cameron (2011b).

Como resultado das análises dos textos, temos:

Quadro 1: Síntese dos recursos de envolvimento e gestos de empatia

\begin{tabular}{|l|l|}
\hline \multicolumn{1}{|c|}{ Recurso de envolvimento realizado } & \multicolumn{1}{|c|}{ Gesto de empatia projetado } \\
\hline PESSOALIZAÇÃO via afetividade & $\begin{array}{l}\text { Entrar na perspectiva do outro - posicionamento } \\
\text { de apoio e compreensão }\end{array}$ \\
\hline $\begin{array}{l}\text { PESSOALIZAÇÃO via pronominalização em } \\
\text { primeira pesSoa + COMPARTILHAMENTO }\end{array}$ & $\begin{array}{l}\text { Permitir a conexão - reconhecimento da } \\
\text { situação do outro pela apresentação de } \\
\text { experiências/vivências pessoais }\end{array}$ \\
\hline COMPARTILHAMENTO + PRESENÇA & $\begin{array}{l}\text { Entrar na perspectiva do outro - colaboração e } \\
\text { posicionamento de apoio por antagonismo }\end{array}$ \\
\hline COLETIVIZAÇÃO inclusiva & Permitir a conexão - disposição para ajudar \\
\hline NARRATIVA & $\begin{array}{l}\text { Permitir a conexão - apresentação de } \\
\text { experiências próprias ou dos outros para criar } \\
\text { identificação }\end{array}$ \\
\hline
\end{tabular}


Ao atentarmos para a conexão entre as alternativas de ENVOLVIMENTO e os gestos de empatia, observamos uma relação de redundância entre eles, pois, no contexto local do registro dos conselhos em revistas, a combinação das opções para criar vínculos e pontos de atenção, somadas às alternativas para atender à necessidade de tomada de perspectiva da situação problemática, resulta em padrões simultâneos de envolvimento e empatia. Tais significados emergem da metarredundância entre possíveis opções de dois conjuntos que agregam significados distintos em uma combinação de recursos linguísticos, que acaba tendo uma relação previsível de realização em determinado contexto.

\section{Considerações finais}

As opções paradigmáticas que estruturam o sistema de ENVOLVIMENTO, tais como afetividade, figurativização, indagação, solicitação, suspense, no discurso de aconselhamento das revistas de nicho selecionadas, revelaram a construção de gestos de empatia nessas trocas interpessoais, ainda que por manifestação de antagonismo, para demonstrar apoio e compreensão aos problemas do leitor. Em outras palavras, o foco no estrato semântico-discursivo permitiu identificar categorias léxico-gramaticais que criam e realizam a troca de significados para instanciar solidariedade.

Verificamos que, para oferecer dicas ao leitor de como este pode resolver um problema, o produtor textual procura estabelecer relações sociais de modo complacente. Assim, no processo de envolver e projetar efeito empático, prevaleceram os recursos mais afeitos à VINCULAÇÃO, que estabelecem a conexão do produtor do texto com o consumidor por meio de categorias que possam exercer uma força de tração entre essas duas instâncias.

No processo de aconselhamento, observamos ainda que a combinação dos dois fenômenos aqui em foco favorece a relação da revista com os potenciais consumidores dos textos, pois permite a particularização das trocas e demonstração de alinhamento ao que se pressupõe como concepções e valores do grupo leitor ideal.

Depreendemos, enfim, formas de Solidariedade construídas por meio de partilha de experiências e de reconhecimento da situação do outro, com base na observação do uso e papel simultâneo de categorias linguísticas vistas como rede de recursos funcionando para determinado fim, de modo a poder corroborar a concepção de que os recursos de ENVOLVIMENTO interpessoal nos permitem apreender os aspectos de gerenciamento interacional na constituição das relações sociais. 
GONÇALVES-SEGUNDO, Paulo Roberto; RIBEIRO, Rafaela Baracat. Involvement and empathy: solidarity built in counseling columns in magazines. Revista do GEL, São Paulo, v. 13, n. 2, p. 211-236, 2016.

Abstract: Our aim, in this paper, based on the systemic-functional approach (HALLIDAY, 2004; MARTIN; WHITE, 2005), is to establish possible realizations of empathy-dyspathy effects, as proposed by Cameron's model (2011a, 2011b, 2011c, 2012a, 2012b), through the instantiation of linguistic resources from the INVOLVEMENT system, developed after a review and an extension of Gonçalves-Segundo's (2011) proposal. To achieve this purpose, we investigated the discursive practice of counselling in Brazilian magazines oriented towards young adult men, young adult women and teenage girls, since these practices are a relevant place for the construction of closer interpersonal bonds between the institution and the reader, who seeks, through the magazine, a potential solution for typical problems concerning his/her social identity. Therefore, this configuration may favor the instantiation of specifically empathic resources in the magazine's replies. The overall results point-mostly, though not exclusively - towards the correlation between the INVOLVEMENT resources linked to bonding and the following gestures of empathy: to enter into the other's world and to allow connection. This points to interactional patterns that emphasize solidarity and interpersonal management that are based, on the one hand, on the sharing of experiences and, on the other hand, on the acknowledgement and on the awareness about the other's problem.

Keywords: Solidarity. Involvement. Empathy.

\section{Referências}

CAMERON, L. Empathy: a review. Living with Uncertainty. Working Paper 1. 2011a. Disponível em: <www.open.ac.uk/researchprojects/livingwithuncertainty/>. Acesso em: 25 fev. 2015.

\begin{tabular}{ccccccc} 
& Metaphor, reconciliation and the dynamics of empathy. Living with \\
\hline Uncertainty. & Working & Paper & 2. & $2011 \mathrm{~b}$. & Disponível & em:
\end{tabular} <www.open.ac.uk/researchprojects/livingwithuncertainty/>. Acesso em: 25 fev. 2015.

Uncertainty. Working Paper 3. 2011c. Disponível em: <www.open.ac.uk/researchprojects/livingwithuncertainty/>. Acesso em: 25 fev. 2015.

The interactional dynamics of empathy: a model. Living with Uncertainty. February, 2012a. Disponível em: 〈www.open.ac.uk/researchprojects/livingwithuncertainty/>. Acesso em: 25 fev. 2015.

. Dyspathy: The dynamic complement of empathy. Living with Uncertainty.

March, Working Paper 5. 2012b. Disponível em:
<www.open.ac.uk/researchprojects/livingwithuncertainty>. Acesso em: 25 fev. 2015.

EGGINS, S.; SLADE, D. Analysing Casual Conversation. London: Continuum, 1997. 
GONÇALVES-SEGUNDO, P. R. Tradição, dinamicidade e estabilidade nas práticas discursivas: um estudo da negociação intersubjetiva na imprensa paulistana. 2011. 447 f. Tese (Doutorado em Filologia e Língua Portuguesa) - Faculdade de Filosofia, Letras e Ciências Humanas, Universidade de São Paulo, São Paulo, 2011.

- Linguística Sistêmico-Funcional e Análise Crítica do Discurso: explorando convergências e explicitando especificidades. Estudos Linguísticos, São Paulo, 43 (3), p. 1282-1297, set./dez. 2014.

HALLIDAY, M. A. K. El lenguaje como semiótica social: la interpretación social del lenguaje y del significado. Tradução de Jorje Ferreiro Santana. Colômbia: Fondo de Cultura Económica, 1994/1978.

An Introduction to Functional Grammar. Revised by Christian M. I. M. Matthiessen. 3rd. edition. London: Arnold, 2004[1985].

HALLIDAY, M. A. K.; HASAN, R. Language, Context, and Text: Aspects of Language in a Social-Semiotic Perspective. Oxford: Oxford University Press, 1989.

LEMKE, J. Textual Politics: Discourse and Social Dynamics. London: Taylor \& Francis, 2005 .

MARTIN, J. English Text: System and Structure. Amsterdam: John Benjamins, 1992.

MARTIN, J. R.; WHITE, P. R. R. The language of evaluation: appraisal in English. New York/Hampshire: Palgrave Macmillan, 2005.

MARTIN, J. R.; ROSE, D. Working with discourse: meaning beyond the clause. London: Continuum, 2007.

MATTHIESSEN, C. M. I. M. Ideas and new directions. In: HALLIDAY, M.; WEBSTER, J. (ed.). Continuum Companion to Systemic Functional Linguistics. London: Continuum, 2009. p. $12-58$.

MATTHIESSEN, C. Systemic Functional Linguistics as appliable linguistics: social accountability and functional approaches. D.E.L.T.A. São Paulo, v. 28, n. esp., p. 435-471, 2012. Disponível em: <http://dx.doi.org/10.1590/S0102-44502012000300002〉. Acesso em: 27 set. 2013.

POYNTON, C. Language and Gender: Making the Difference. Geelong, Vic: Deakin University Press, 1985.

TANNEN, D. Talking voices: repetition, dialogue, and imagery in conversational discourse. New York: Cambridge University Press, 1994/1989.

WEBSTER, J. J. An Introduction to Continuum Companion to Systemic Functional Linguistics. In: HALLIDAY, M.; WEBSTER, J. (ed.). Continuum Companion to Systemic Functional Linguistics. London: Continuum, 2009. p. 1-11.

Submetido em 19/10/2015

Aceito em 25/04/2016. 